\title{
Assessing the relative efficiency of termite sampling methods along a rainfall gradient in African savannas
}

\author{
Andrew B. Davies ${ }^{1, *}$, Paul Eggleton ${ }^{2}$, Berndt J. van Rensburg ${ }^{1, \dagger}$, \& Catherine L. Parr ${ }^{3, \$}$ \\ ${ }^{1}$ Centre for Invasion Biology, Department of Zoology and Entomology, University of Pretoria, Pretoria, \\ 0002, South Africa, ${ }^{2}$ Soil Biodiversity Group, Entomology Department, The Natural History Museum, \\ Cromwell Road, London, SW7 5BD, United Kingdom, ${ }^{3}$ Environmental Change Institute, School of \\ Geography and the Environment, Oxford University Centre for the Environment, South Parks Road, \\ Oxford, OX1 3QY, United Kingdom \\ Current address: `School of Biological Sciences, University of Queensland, St. Lucia, QLD 4072, \\ Australia, ${ }^{\star}$ School of Environmental Sciences, University of Liverpool, Liverpool, L69 3GP, United \\ Kingdom
}

*Corresponding author: Andrew Davies - e-mail: abdavies@zoology.up.ac.za

\begin{abstract}
Although termites are ecosystem engineers in tropical and sub-tropical environments, the study of termite ecology is often constrained by sampling difficulties and a lack of established sampling protocols, particularly for savannas. The efficiency and relevance of different methods along climatic gradients, even within a single biome, is largely unknown. Here, we compare the relative contribution of two commonly used sampling methods, cellulose baits and active searching transects, in quantifying savanna termite diversity along a rainfall gradient in South Africa; sampling was conducted during the wet season across four markedly different savanna types. We also assessed the usefulness
\end{abstract}


of different forms of baiting techniques. The relative efficiency of sampling method varied with annual rainfall. In arid savannas, baiting was as effective as active searching transects at sampling termite diversity and we recommend the use of baiting rather due to it being less labour intensive. In savannas of moderately low to intermediate rainfall, baiting and transects sampled different termite species and so both are deemed necessary for an accurate assessment of termite diversity. In contrast, in wetter savannas transects gave a better assessment of diversity, with cellulose baits not contributing much to diversity assessment. The efficiency of baiting techniques differed across the rainfall gradient, with baits needing to be left in the field for a longer period in more arid savannas. We conclude that habitat type, even within a single biome, will determine the sampling method or methods necessary to quantify termite diversity accurately.

Keywords: active searching transects; baiting; biodiversity assessments; feeding groups; invertebrate sampling; sampling protocols; South Africa

\section{TERMITES (BLATTODEA: TERMITIDOIDAE) ARE IMPORTANT ECOSYSTEM ENGINEERS IN} TROPICAL AND SUB-TROPICAL HABITATS. They are responsible for the redistribution of soil particles and alter the mineral and organic composition of soils, as well as their hydrology (Jones et al. 1994, Konaté et al. 1999, Mando et al. 1996). They are considered the dominant invertebrate decomposers in such tropical systems (Collins 1981, Holt 1987, Schuurman 2005) and hence influence nutrient cycling and distribution (Holt \& Coventry 1990, Lepage et al. 1993). Termites are also a moderately diverse group comprising a number of feeding groups, including: wood feeders, grass harvesters 
and soil feeders, which exert different ecological effects on ecosystems (Donovan et al. 2002, Josens 1983).

Despite this, detailed knowledge of termites in ecosystems is scarce, (Dangerfield \& Schuurman 2000, Dawes-Gromadzki 2003, Davies et al. 2010), due to taxonomic and sampling difficulties, especially in savannas. To address these difficulties and construct relevant and effective conservation management plans for savannas, comparable sampling protocols need to be developed to allow termites to be sampled quantitatively. Jones \& Eggleton (2000) designed a sampling protocol for tropical rain forests consisting of an active searching transect, which is comparable across forested areas (see e.g. Donovan et al. 2002, Eggleton et al. 2002, Gathorne-Hardy et al. 2001), but has not been tested along a climatic gradient, and may be unsuitable for drier systems, such as savannas where soils are harder, making digging difficult. Furthermore, much of termite diversity in dry habitats is inside mounds rather than between them, making active searching potentially less effective. Different sampling methods also target different termite groups. For example, baiting, especially with toilet paper rolls, is commonly used in drier regions (Le Fage et al. 1973), but is really only useful for wood-feeding termites and does not provide absolute abundance data because not all termites present are sampled. Active searching transects, on the other hand, sample all termites, but are labour intensive and often less effective for hard savanna soils (although see e.g. Ferrar 1982, Dawes-Gromadzki 2005, 2008).

There have been several attempts to develop standardised savanna sampling protocols analogous to the Jones \& Eggleton tropical forest transects (e.g., see DawesGromadzki 2003, Zeidler et al. 2004), but none of these have been tested along a climatic 
gradient to test for optimality. Also uncertain is the frequency that baits should be checked in the field, and whether they should be buried or placed on the soil surface. Because savannas are highly variable environments, differing markedly in vegetation and climate (House et al. 2003); sampling methods in one savanna system may be inappropriate for another.

Here, the relative efficiency of two sampling methods (cellulose baits and active searching transects) for sampling termite diversity in savannas was assessed. We were interested in the contribution each method made to the quantification of termite diversity along a rainfall gradient, and whether using both methods is always preferable. Different baiting techniques along the savanna rainfall gradient were also assessed because baiting is so frequently used in savannas. Specifically, we examine how long baiting experiments should last, whether baits should be buried or on the soil surface, and how climate influences the effectiveness of these approaches.

\section{METHODS}

STUDY SITE.- Sampling was conducted in four distinct savanna vegetation types along a rainfall gradient spanning some $700 \mathrm{~km}$ in two of South Africa's major reserves: Kruger National Park (KNP) and Hluhluwe-iMfolozi Park (HiP). These are in the eastern part of the country and are subtropical with a distinct summer rainfall pattern.

The savanna types were: mopane woodland (Mopani, northern KNP, $450 \mathrm{~mm}$ mean annual precipitation (MAP)), Acacia savanna (Satara, central KNP, 550 mm MAP), Terminalia woodland (Pretoriuskop, southern KNP, $750 \mathrm{~mm}$ MAP) and mesic Acacia savanna (Hluhluwe section of HiP, 900 mm MAP). This study forms part of a larger 
programme (see Davies et al., 2012) and sampling in KNP was at a series of experimental burning plots (see Biggs et al. 2003 and van Wilgen et al. 2007). Three sets of four sampling plots (12 plots per savanna type except for Hluhluwe where 11 plots were used) spaced $10-20 \mathrm{~km}$ apart were selected from within each of the savanna types. The four in each set of plots form part of a burning experiment, but are representative of each savanna type and its fire regimes. Fire effects were controlled for because the same four burning regimes were sampled in each habitat. Termites display remarkable resistance to fire (Davies et al. 2012) and so different burning regimes should not affect sampling techniques.

TERMITE SAMPLING.-Termites were sampled using two methods: cellulose baits ('baits') and active searching transects ('transects'). Sampling was conducted during the austral summer (wet season) from November 2008 to February 2009, the peak of termite activity (Dawes-Gromadzki \& Spain 2003, Davies 2010). These are sampling methods often used in savannas (baits: see Dawes-Gromadzki 2003, Ferrar 1982, Schuurman 2005, transects, Ferrar 1982, Dawes-Gromadzki 2005, 2008), yet their relative efficiency across different savanna types has not yet been investigated.

Forty toilet roll baits were placed on each plot (see La Fage 1973), in a grid of five by eight baits, spaced five metres apart. In order to test differences in bait placement (position relative to the soil and time left in the field), half (twenty) of the baits were placed on the soil surface, with litter brushed aside to ensure direct contact was made between the soil and the bait (Dawes-Gromadzki 2003). These baits were wrapped around the middle with tape to prevent unravelling and secured to the soil surface using 
an aluminium peg placed through the centre hole of each toilet roll. Covering of the baits to prevent damage during a rainfall event was not necessary as the baits quickly dried out and still attracted termites (A. B. Davies, pers. obs.). Furthermore, we expected that covering baits might alter micro-climatic conditions around them. The other half of the baits (20) was buried below the soil surface to a depth of $c a .2 \mathrm{~cm}$. Each line of eight baits consisted of four buried and four surface baits with the position of the baits alternating. Baits were checked for termites and assessed for termite attack after intervals of 5, 14, 28 and 56 days. Five surface and five buried baits were removed (without replacement) each time, and any termites present were sampled. The proportion of baits attacked at each census was recorded as a frequency of termite attack. The baits were then scored according to the intensity of attack (IA). Baits that were completely intact were scored 0 , and more damaged baits were scored: $1=1-25 \%$ consumed, $2=26-$ $50 \%$ consumed, $3=51-75 \%$ consumed, $4=76-99 \%$ consumed and $5=99-100 \%$ consumed (following Dawes-Gromadzki 2003). Disturbed baits that were either destroyed or no longer in direct contact with the soil were excluded. The frequency of attack was calculated from the number of attacked baits (separately for buried and surface) at each time interval.

For the transects, two 50 by 2 m belt transects (modified from Jones \& Eggleton 2000) were laid out on each plot, with each sub-divided into ten 5 by 2 m sections and each section searched for termites (i.e. excavating soil and searching dead wood, termite nests and other microhabitats) for ten person minutes. . Vegetation up to a height of one meter was searched, including termite runways up tree trunks. All termite species in a section were recorded as well as the number of occurrences. An occurrence is recorded 
when a population of termites of one species at one point (bait or section of transect) is sampled (following Davies et al. 2003).

TERMite IdENTIFICATIONS.--Termites were identified at the Natural History Museum, London, the University of Pretoria and the National Collection of Insects, Pretoria. Specimens were identified to species, where possible, using soldier castes whenever available (when soldiers were not present, workers were used). Where this was not possible, morphospecies were used, and where even this was problematic the specimens were treated as an aggregate for that specific genus. Voucher specimens are lodged at the University of Pretoria, South Africa.

ANALYSES. - The relative efficiency of sampling method (transect vs. baiting) was assessed by (i) how many species each method sampled in each savanna type, (ii) species turnover between methods, and (iii) the feeding group diversity captured by each method. For these comparisons, baiting data from both surface and buried baits were combined.

Student's t-tests were used to compare the mean number of species sampled per plot by each method at each savanna site along the rainfall gradient. We then investigated the shared and unique species sampled with each method and the composition of the feeding groups sampled in each savanna type. Termites were classified into feeding groups (I - IV) based on the classification described by Donovan et al. (2001). Different termite feeding groups play different ecological roles and so estimating how sampling methods affect the suite of termites collected is informative. 
For comparisons of baiting techniques, generalized linear mixed models with Poisson (intensity of termite attack and species density) or Binomial (frequency of attack) error distributions were fitted to examine correlations between time (number of days in the field), bait position (surface or buried), site (savanna habitat) and their interactions with species density (number of species sampled per unit area [see Gotelli \& Colwell 2001]), intensity of termite attack (IA) and the frequency of attack (FA), with the sampling plot set as a random effect. Models were ranked according to sample-sizecorrected Akaike Information Criterion (AICc) and the best model for each response variable (species density, IA and FA) selected.

\section{RESULTS}

Termites from 18 genera and 5 subfamilies were sampled. The distribution of feeding groups (FG) was as follows: FGI, 50 percent, FGII, 33 percent, FGIII, 11 percent and FGIV, 6 percent (Table S1).

BAITING RELATIVE TO ACTIVE SEARCHING.--Species densities sampled between methods were not significantly different at the arid sites (Mopani and Satara). In contrast, transects yielded significantly more species than baiting at the wetter sites, Pretoriuskop $\left(T_{22,}=\right.$ $5.70, P<0.0001)$ and Hluhluwe $\left(T_{20}=2.07, P=0.0517\right)$. However, at all sites transects sampled a larger number of species, and more unique species than baits, particularly at Pretoriuskop, the second wettest site (Table 1).

A comparison of feeding groups (FG) shows that at the more arid sites (Mopani and Satara) FG composition is independent of sampling method (Fig. 1). However, at the 
wetter sites (Pretoriuskop and Hluhluwe), the FGs sampled and their relative contributions differed with sampling method: transects resulted in a wider range of sampled FGs. This is particularly pronounced at Pretoriuskop where FGIII becomes more common and FGIV is recorded with transects only (Fig. 1). At all sites, baits sampled almost entirely FGII, although at the wet sites some contained FGIII.

CELLulose BAITS.- Species density recorded at baits varied significantly over time, more species with time at the more arid sites, but decreasing at the last bait check at wetter sites (Pretoriuskop and Hluhluwe) $\left(X^{2}{ }_{3}=37.97, P<0.001\right.$; Fig. 2a). Across all sites, bait position significantly affected species density $\left(X^{2}{ }_{1}=9.62, P<0.01\right)$; for days 1 -28 , species density was greater at buried baits, but at the last bait check (56 days) it was similar for buried and surface baits (Fig. 2b). The effect of savanna site on the number of species sampled was also significant $\left(X^{2}{ }_{3}=34.42, P<0.001\right)$. Highest species density was at Satara for all bait checks and lowest at Mopani for all bait checks except the last, where Mopani had greater density than both wetter sites (Fig. 2a). The interactions between bait position and time $\left(X^{2}{ }_{3}=14.55, P<0.01\right)$ and savanna site and time $\left(X^{2}{ }_{9}=\right.$ 21.83, $P<0.01)$ were also important for explaining patterns in species density (Fig. 2a).

There was a significant positive correlation between mean intensity of termite attack (IA) and time $\left(X^{2}{ }_{3}=386.71, P<0.001\right.$, Fig. 2c). IA increased with time at all sites with a steep increase between days 28 and 56 for the arid (Mopani and Satara) sites, but not the wet sites (Pretoriuskop and Hluhluwe). Bait position also had a significant effect on IA $\left(X^{2}{ }_{1}=77.10, P<0.001\right)$, with higher attack recorded at buried $(0.69 \pm \operatorname{SE} 0.02)$ than surface $(0.35 \pm \mathrm{SE} 0.01)$ baits. Site also had a significant effect on IA $\left(X^{2}{ }_{3}=31.40\right.$, 
$P<0.001$, Fig. 2c), with higher attack levels at Satara than the other sites. All two-way interactions were important for explaining patterns in IA (time x position: $X^{2}{ }_{3}=24.84, \mathrm{P}$ $<0.001$; time $\mathrm{x}$ site: $\left.X^{2}{ }_{9}=30.88, \mathrm{P}<0.001\right)$; position $\mathrm{x}$ site: $X^{2}{ }_{3}=13.34, \mathrm{P}<0.01$ ).

Mean frequency of attack (FA) varied significantly, with higher incidences of attack as time progressed at all sites except Hluhluwe where FA decreased between 28 and 56 days $\left(X^{2}{ }_{3}=31.98, P<0.001\right)$. In contrast, the drier sites (Mopani and Satara) showed markedly steeper increases from 28 to 56 days (Fig. 2d). Across all sites, FA was also significantly greater at buried $(43.27 \pm \mathrm{SE} 2.75 \%)$ than surface $(27.96 \pm \mathrm{SE} 2.50 \%)$ baits $\left(X^{2}{ }_{1}=45.14, P<0.001\right)$. The effect of site on FA was also significant $\left(X^{2}{ }_{3}=31.98\right.$, $P<0.001$ ), with the highest incidences of attack at Satara for all bait checks (Fig. 2d). As with IA, all two-way interaction terms were important for explaining variation in FA (time $\mathrm{x}$ position: $X_{3}^{2}=22.14, \mathrm{P}<0.001$; time $\mathrm{x}$ site: $X^{2}{ }_{9}=48.61, \mathrm{P}<0.001$; position $\mathrm{x}$ site: $\left.X_{3}^{2}=35.13, \mathrm{P}<0.001\right)$.

\section{DISCUSSION}

Our results suggest that the importance of active searching transects and cellulose baits as methods for sampling overall termite diversity varies with savanna type. Similarly, how baiting is conducted (i.e. timing and position) should depend on where along a climatic gradient sampling occurs.

RELATIVE CONTRIBUTIONS OF TRANSECTS AND BAITING.- - In the most arid savanna (450 mm MAP), mean termite species density per plot did not vary with sampling method. Therefore, if only species density estimates are required in arid savannas, either method 
suffices (see also Zeidler et al. 2004, with broadly similar results). Furthermore, most of the species sampled were shared by both methods, with neither providing many unique species; indeed most termites at this site are FGII, a group sampled effectively by cellulose baits (Table S1). These results imply that at this site baiting may well be the preferred sampling method as it is less labour intensive. For savannas of intermediate to moderately low rainfall, such as Satara (550 mm MAP), the termite diversity sampled appeared similar based on the species density per plot, and either method might seemingly sample the termite diversity adequately. However, 40 percent of species sampled were unique to transects while only one species (7\%) was sampled with baiting alone. Transects are clearly a more effective sampling method here. In both the wetter savanna sites, transects sampled more species than baits. Importantly, only one species was sampled with baits alone (Promirotermes spp.), and this was found only at Hluhluwe (the wettest site) (it was also sampled with transects at Pretoriuskop). This species is, however, a soil-feeder and its sampling with baits is probably a chance event, it was likely feeding on soil brought into the cellulose baits by other termites. Transects are thus a more effective method for sampling termite diversity in mesic savanna habitats, cellulose baits not adding much to a species inventory. Dawes-Gromadzki (2008) sampled termites in a tropical Australian savanna with high annual rainfall using both active searching and baits (cellulose and wooden) and also recorded more termites with active searching.

If measures of relative abundance are required then baiting would add significant information in the arid savanna sites (more occurrences of termites were sampled this way) and little in the wetter sites (here more termites were encountered with transects). 
Although not directly tested for here, baiting may well provide a better measure of termite activity than transects in many savanna sites. This because signs of activity detected with transects (e.g. tunnelling, sheeting) may only be evident immediately after termites have been active, which is likely to be soon after rainfall events, a fairly sporadic occurrence in many savanna systems. Baiting on the other hand provides a quantitative assessment of activity (see Davies et al. 2012).

BAITING TECHNIQUES.- There were profound differences in termite diversity and activity levels recorded at the baits between the arid and mesic savanna sites. Although overall species density increased significantly over time at all sites, the difference between the $3^{\text {rd }}$ and $4^{\text {th }}$ censuses is of consequence (Fig. 2a). It appears that the temporal scale of a baiting protocol is of importance and should be modified according to the savanna type being sampled and not just the presentation or type of bait used (see also Taylor et al. 1998, Dawes-Gromadzki 2003). At the arid sites, the number of species sampled, intensity of attack and frequency of attack, increased substantially between the $3^{\text {rd }}$ and $4^{\text {th }}$ censuses, which contrasts to that of the wetter sites which show a decrease or levelling off. In northern Australia over this same time scale (eight weeks), Dawes-Gromadzki (2003) also found a decrease in species density sampled (although attack levels increased), however, these changes may have been seasonal, in contrast to our study which was conducted only within the wet season. At the wettest sites in our study (particularly Hluhluwe), fungus was found growing on many baits at the last census, which may repel termites (Abensperg-Traun 1993, Dawes-Gromadzki 2003) and could explain why activity and density recorded decreased. This would imply that in mesic 
savannas, there is no benefit to leaving baits in the field for long periods ( $>56$ days). In contrast, when MAP $<600 \mathrm{~mm}$, a longer period may be required to sample the termite assemblages adequately.

Our results indicate that bait position is also important. In contrast with studies in desert regions (e.g., Ettershank et al. 1980; Taylor et al., 1998), but in agreement with savanna studies (e.g., Dawes-Gromadzki 2003), we found that buried baits were more attractive to termites during the first three censuses. Dawes-Gromadzki (2003) suggested that savanna termites contrast with desert populations in that they do not use thermal shadows to locate surface baits (Ettershank et al. 1980) due to higher levels of canopy cover (or grass biomass). Our results support this, although the attractiveness of surface and buried baits did not differ by the last census (56 days) which is considerably less time for this to occur than in northern Australia (Dawes-Gromadzki 2003). We suggest this could be due to lower levels of canopy cover, different feeding habits of African termites or higher levels of activity. It also implies that if there are no time constraints for a study, surface baits may be better to use as they are less labour intensive to establish.

SYNTHESIS AND RECOMMENDATIONS.-We propose that transects should be used in termite diversity studies in all but the driest sites, where there is a much less predictable occupation of between-mound spaces and baiting approaches become more useful. At wet savanna sites (>750 mm MAP), baiting added little new information and so we recommend only transects be used. If baiting is used, our results suggest that different designs need to be employed along climatic gradients; generally baits should be left out 
for longer ( $>$ one month) in drier habitats, and for such longer experiments bait position is unimportant.

\section{Acknowledgements}

We thank the many volunteers who assisted with field work as well as South African National Parks, Ezemvelo KZN Wildlife and the Zululand Tree Project for logistical support. Vivienne Uys is thanked for assistance with initial termite identifications. This research was funded by a Rufford Small Grants Innovation Award as well as the University of Pretoria. CLP thanks the Trapnell Fund and the Oxford University John Fell Fund.

\section{References}

ABENSPERG-TRAUN, M. 1993. A comparison of two methods for sampling assemblages of subterranean, wood-eating termites (Isoptera). Aust. J. Ecol. 18: 317-324.

Biggs, R., H. C. Biggs, T. T. Dunne, N. Govender, And A. L. F. Potgieter. 2003. Experimental burn plot trial in the Kruger National Park: history, experimental design and suggestions for data analysis. Koedoe 46: 1-15.

Collins, N. M. 1981. The role of termites in the decomposition of wood and leaf litter in the southern Guinea savanna of Nigeria. Oecologia 51: 389-399.

DANGERFIEld, J. M., T. S. MCCARTHY, AND W. N. ElLERY. 1998. The mound-building termite Macrotermes michaelseni as an ecosystem engineer. J. Trop. Ecol. 14: 507520. 
DANGERFIELD, J. M. AND G. SCHUURMAN. 2000. Foraging by fungus-growing termites (Isoptera: Termitidae, Macrotermitinae) in the Okavango Delta, Botswana. J. Trop. Ecol. 16: 717-731.

DAVIES, A. B. 2010. Termite responses to long term burning regimes in southern African savannas: patterns, processes and conservation. MSc dissertation, University of Pretoria, Pretoria, South Africa.

Davies, A. B., C. L. ParR, AND B. J. van RensbuRg. 2010. Termites and fire: Current understanding and future research directions for improved savanna conservation. Austral Ecol. 35: 482-486.

Davies, A. B., P. Eggleton, B. J. van Rensburg, and C. L. Parr. 2012. The pyrodiversity-biodiversity hypothesis: a test with savanna termite assemblages. J. Appl. Ecol. 49: 422-430.

DAWES-GROMADZKI, T. Z. 2003. Sampling subterranean termite species diversity and activity in tropical savannas: an assesment of different bait choices. Ecol. Entomol. 28: 397-404.

DAWES-GROMADZKI, T. Z. 2005. Bugs beneath the surface: the functional significance of soil macroinvertebrates to landscape health in Australia's tropical savannas. Insect Science 12: 307-312.

DAWES-GROMADZKI, T. Z. 2008. Abundance and diversity of termites in a savanna woodland reserve in tropical Australia. Australian Journal of Entomology 47: 307314. 
DAWES-GromadZKi, T. Z., AND A. Spain. 2003. Seasonal patterns in the activity and species richness of surface-foraging termites (Isoptera) at paper baits in a tropical Australian savanna. J. Trop. Ecol. 19: 449-456.

Donovan, S. E., P. Eggleton, And D. E. Bignell. 2001. Gut content analysis and a new feeding group classification of termites. Ecol. Entomol. 26: 356-366.

Donovan, S. E., P. Eggleton, And A. Martin. 2002. Species composition of termites of the Nyika plateau forests, northern Malawi, over an altitudinal gradient. Afr. J. Ecol. 40: $379-385$.

Eggleton, P., D. E. Bignell, S. Hauser, L. Dibog, L. Norgrove, And B. Madong. 2002. Termite diversity across an anthropogenic disturbance gradient in the humid forest zone of West Africa. Agr. Ecosyst. Environ. 90: 189-202.

ETtershank, G., J. A. ETtershANK, AND W. G. WHitFORD. 1980. Location of food sources by subterranean termites. Environ. Entomol. 9: 645-648.

FERRAR, P. 1982. Termites of a South African savanna. I. List of species and subhabitat preferences. Oecologia 52: 125-132.

FERRAR, P. 1982. Termites of a South African savanna. III. Comparative attack on toilet roll baits in subhabitats. Oecologia 52: 139-146.

GATHORNE-HARDY, F., SyAUKANI AND P. EGGLETON. 2001. The effects of altitude and rainfall on the composition of the termites (Isoptera) of the Leuser Ecosystem (Sumatra, Indonesia). J. Trop. Ecol. 17: 379-393.

Gotelli, N. J., AND R. K. COLWELl. 2001. Quantifying biodiversity: procedures and pitfalls in the measurement and comparison of species richness. Ecol. Lett. 4: 379391. 
HoLT, J. A. 1987. Carbon mineralization in semi-arid northeastern Australia: the role of termites. J. Trop. Ecol. 3: 255-263.

HoLt, J. A., AND R. J. COVENTRY. 1990. Nutrient cycling in Australian savannas. J. Biogeogr. 17: 427-432.

House, J. I., S. ARChER, D. D. BRESHEARS, AND R. J. SCHOles. 2003. Conundrums in mixed woody-herbaceous plant systems. J. Biogeogr. 30: 1763-1777.

JONES, C. G., J. H. LAWTON, AND M. SHACHAK. 1994. Organisms as ecosystem engineers. Oikos 69: 373-386.

JONES, D. T., AND P. EGGLETON. 2000. Sampling termite assemblages in tropical forests: testing a rapid biodiversity assessment protocol. J. Appl. Ecol. 37: 191-203.

Josens, G. 1983. The soil fauna of tropical savannas. III. The termites. In F. Bouliere (Ed.). Ecosystems of the World 13: Tropical savannas, pp. 505-524. Elsevier, Amsterdam, Netherlands.

Konaté, S., X. Le rouX, D. TeSsier, AND M. LePAGe. 1999. Influence of large termitaria on soil characteristics, soil water regime, and tree leaf shedding pattern in a West African savanna. Plant Soil 206: 47-60.

Le FAGe, J. P., W. L. NutTing, AND M. I. HAVERTY. 1973. Desert subterranean termites: A method for studying foraging behavior. Environ. Entomol. 2: 954-956.

Lepage, M., L. AbBadie, AND A. MARiotti. 1993. Food habits of sympatric species (Isoptera, Macrotermitinae) as determined by stable carbon isotope analysis in a Guinean savanna (Lamto, Côte d'Ivoire). J. Trop. Ecol. 9: 303-311.

MANDO, A., L. StroosniJder, AND L. BRUSSAARD. 1996. Effects of termites on infiltration into crusted soil. Geoderma 74: 107-113. 
SCHUURMAN, G. 2005. Decomposistion rates and termite assemblage composition in semiarid Africa. Ecology 86: 1236 - 1249.

TAYlor, H. S., W. P. MACKAy, J. E. Herrick, R. A. Guerrero, AND W. G. Whitford. 1998. Comparison of field methods to detect termite activity in the northern Chihuahuan desert (Isoptera). Sociobiol. 32: 1-16.

VAN Wilgen, B. W., N. Govender, AND H. C. BIGGS. 2007. The contribution of fire research to fire management: a critical rewiew of a long-term experiment in the Kruger National Park, South Africa. Int. J. Wildland Fire 16: 519 - 530.

ZEIDLER, J., S. HANRAHAN, AND M. SCHOLES. 2004. Determining termite diversity in arid Namibian rangelands - a comparison of sampling methods. Afr. Zool. 39: 285-292. 
Table 1. Total, shared and unique species sampled by two methods: active searching (AS) and cellulose baits (B) in four savanna sites in southern Africa. Sites are arranged in ascending order of mean annual precipitation received, Mopani being the driest and

Hluhluwe the wettest site.

\begin{tabular}{|c|c|c|c|c|c|c|c|c|}
\hline \multirow{2}{*}{$\begin{array}{l}\text { Savanna site } \\
\text { Sampling method }\end{array}$} & \multicolumn{2}{|c|}{ Mopani } & \multicolumn{2}{|c|}{ Satara } & \multicolumn{2}{|c|}{ Pretoriuskop } & \multicolumn{2}{|c|}{ Hluhluwe } \\
\hline & AS & $\mathrm{B}$ & AS & $\mathrm{B}$ & AS & $\mathrm{B}$ & AS & $\mathrm{B}$ \\
\hline Total number of species & 6 & 5 & 14 & 9 & 15 & 5 & 14 & 9 \\
\hline Shared species & 4 & 4 & 8 & 8 & 5 & 5 & 8 & 8 \\
\hline Unique species & 2 & 1 & 6 & 1 & 10 & 0 & 6 & 1 \\
\hline
\end{tabular}


Appendix S1. Occurrence of termite species for each method summed for all 12 sites at each savanna habitat. For bait data, occurrence values are for all time checks. The Feeding Group for each species is also indicated. AS = active searching transects, SB = surface baits, $B B=$ buried baits and $F G=$ Feeding Group.

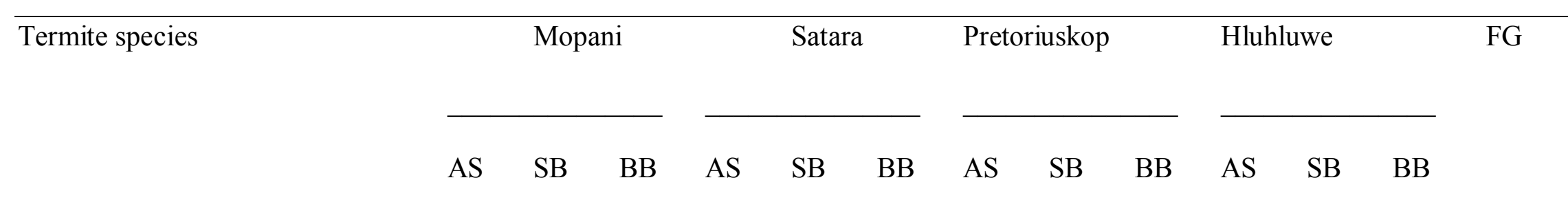

\section{Hodotermitidae}

Hodotermes mossambicus

2

\section{Termitidae}

\section{Macrotermitinae}

Allodontermes rhodesiensis

Ancistrotermes latinotus

Macrotermes michaelseni

Macrotermes natalensis

Microtermes spp.

\begin{tabular}{|c|c|c|c|c|c|c|c|c|c|c|c|}
\hline 2 & - & - & 16 & 7 & 9 & 3 & 6 & 4 & 20 & 8 & 4 \\
\hline - & 3 & 1 & 22 & 9 & 19 & 17 & 3 & 17 & 18 & 3 & 4 \\
\hline 4 & 1 & 11 & 3 & 9 & 16 & - & - & - & 1 & - & - \\
\hline - & - & - & 1 & - & 1 & - & - & - & 7 & - & 1 \\
\hline 7 & 36 & 66 & 34 & 44 & 86 & 46 & 39 & 38 & 31 & 27 & 28 \\
\hline
\end{tabular}


Odontotermes sp. 1

Odontotermes sp. 2

Odontotermes sp. 3

Apicotermitinae

Adaiphrotermes spp.

Alyscotermes spp.

Anenteotermes spp.

Astalotermes spp.

\section{Termitinae}

Amitermes hastatus

Amitermes messinae

Angulitermes spp.

Cubitermes spp.

Lepidotermes spp.

Microcerotermes spp.

Promirotermes spp.

$\begin{array}{rllllllllllll}- & - & - & - & - & 1 & 3 & - & - & 3 & - & - & \text { II } \\ - & - & - & 3 & - & 1 & 1 & 1 & - & 17 & 5 & 5 & \text { II } \\ 2 & - & 1 & 18 & 4 & 7 & - & - & - & 1 & 2 & 2 & \text { II }\end{array}$

(1)

$\begin{array}{lllllllllllll}- & - & - & - & - & - & 7 & - & - & 10 & - & - & \text { III } \\ - & - & - & - & - & - & 7 & - & - & 1 & - & - & \text { III } \\ - & - & - & - & - & - & 6 & - & - & - & - & - & \text { III } \\ - & - & - & 6 & - & - & 38 & 2 & 2 & 8 & 1 & 1 & \text { III }\end{array}$

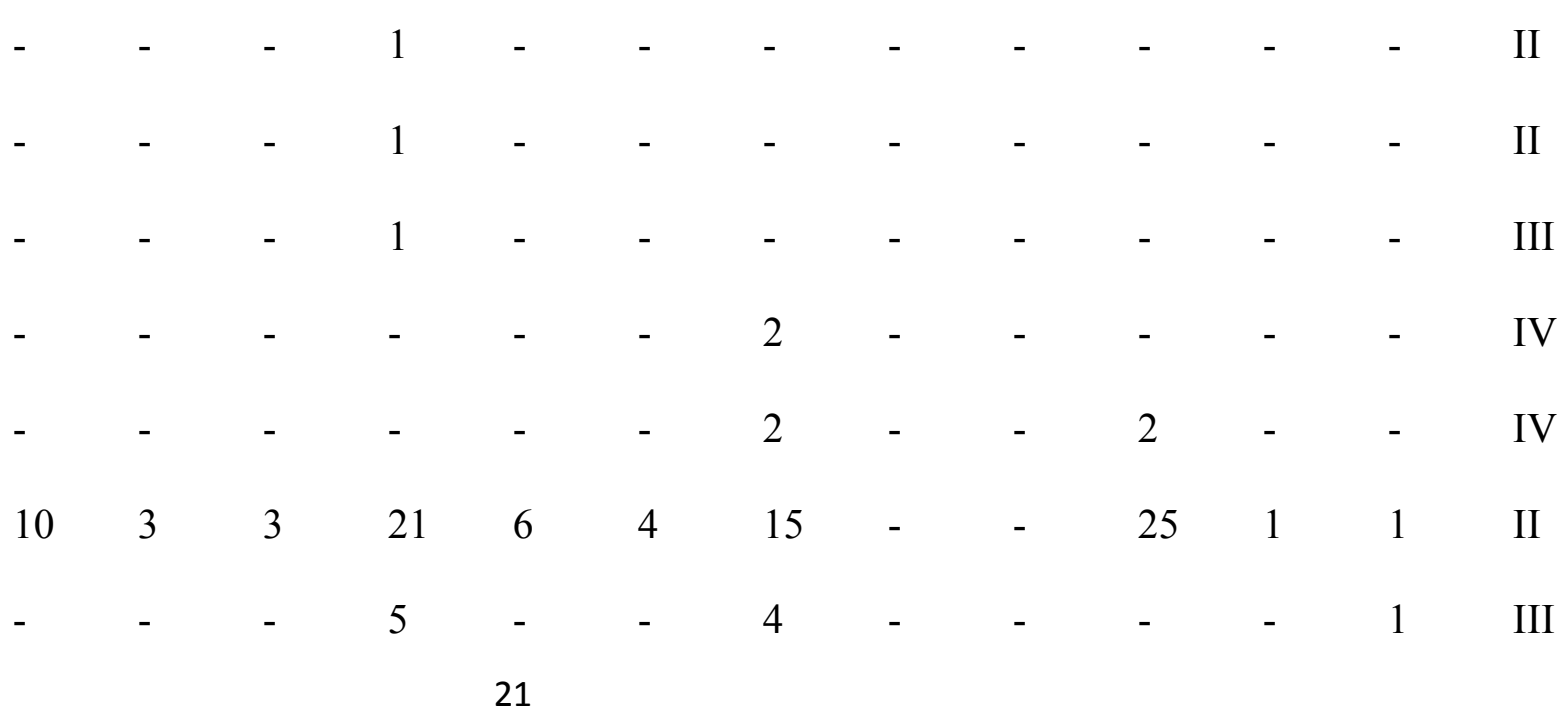




\section{Nasutitermitinae}

Trinervitermes trinervoides

Rhadinotermes coarctatus

Total number of occurrences 
FIGURE 1. Feeding group composition of the termite assemblages sampled at each savanna site using baits and active searching. Feeding group I comprises the lower termites which feed on dead wood and grass; group II is made up of Termitidae with a range of feeding habits which include dead wood, grass, leaf litter and micro-epiphytes; group III feed in the organic rich upper soil layers and are also Termitidae; and group IV contains the true soil-feeders which ingest mineral soil, again all Termitidae. Sites are arranged in order of increasing mean annual precipitation: $\mathrm{M}=$ Mopani, $\mathrm{S}=$ Satara, $\mathrm{P}=$ Pretoriuskop and $\mathrm{H}=$ Hluhluwe. $\mathrm{AS}=$ active searching transects and baits $=$ cellulose baits.

FIGURE 2. Mean ( \pm SE) (a) number of species recorded at baits, (b) number of species recorded at surface and buried baits (all sites pooled), (c) intensity of attack on baits, and (d) percentage of baits attacked by termites at four censuses across four savanna sites. 
Figure 1

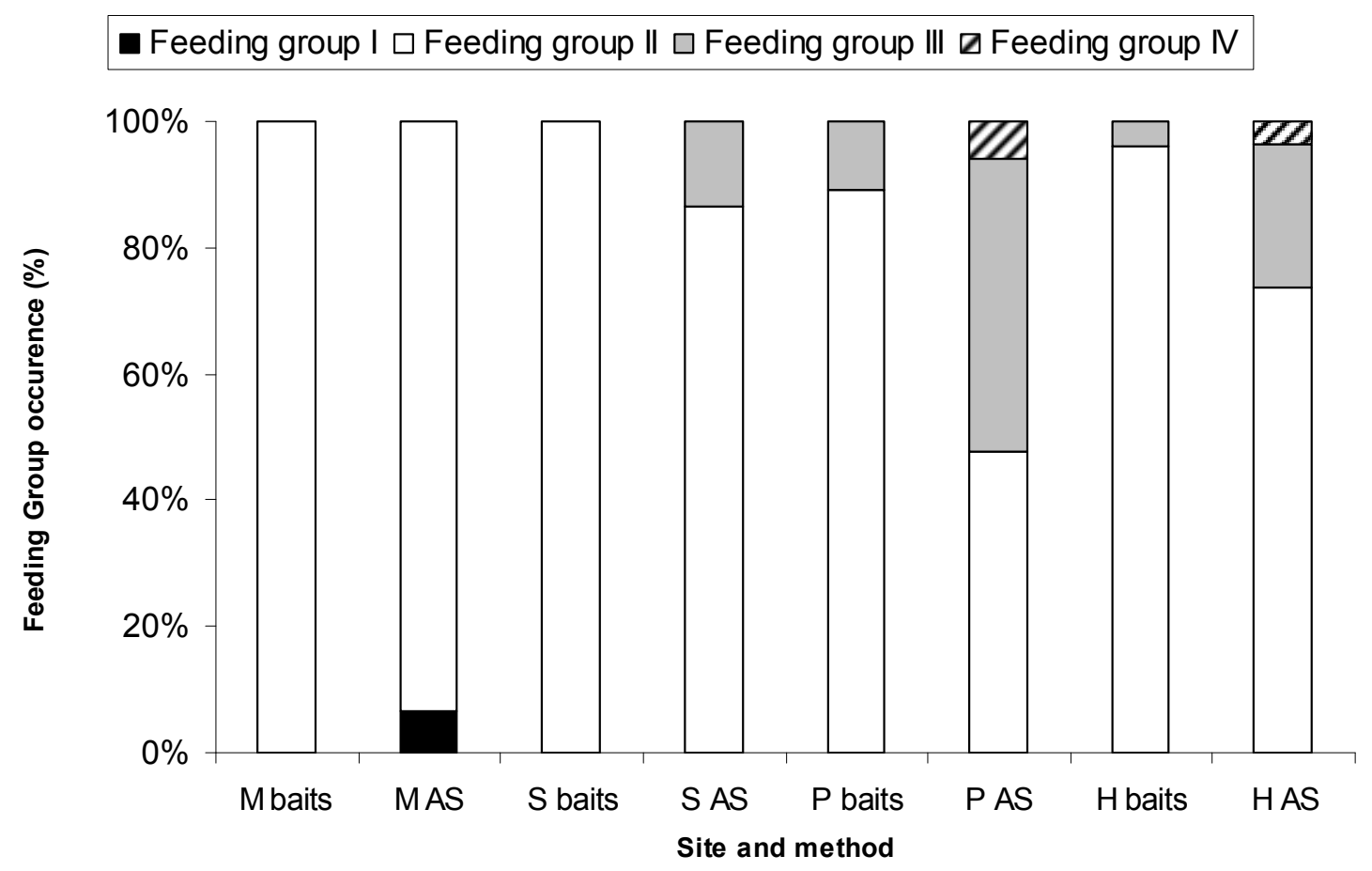


Figure 2

(a)

-Mopani $\rightarrow$-Satara $\rightarrow$-Pretoriuskop $\rightarrow$ Hluhluwe

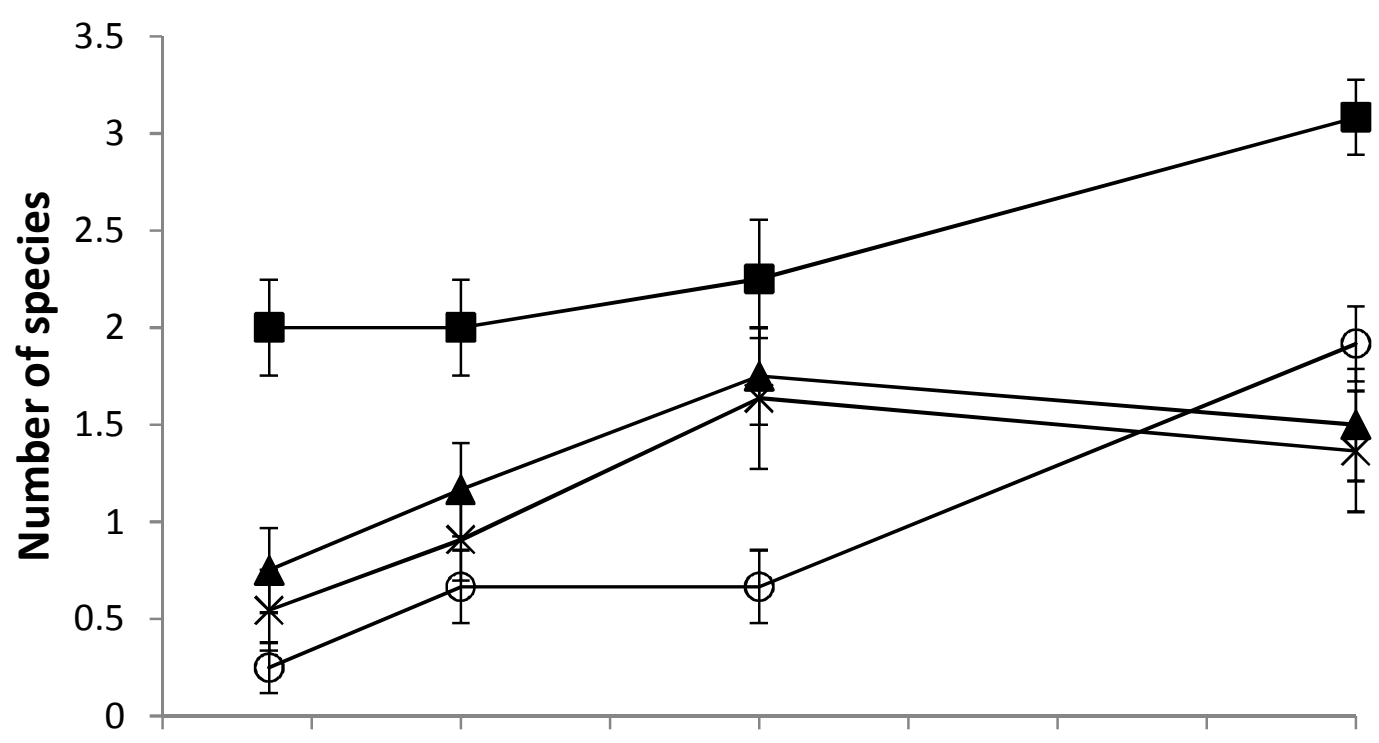

(b)

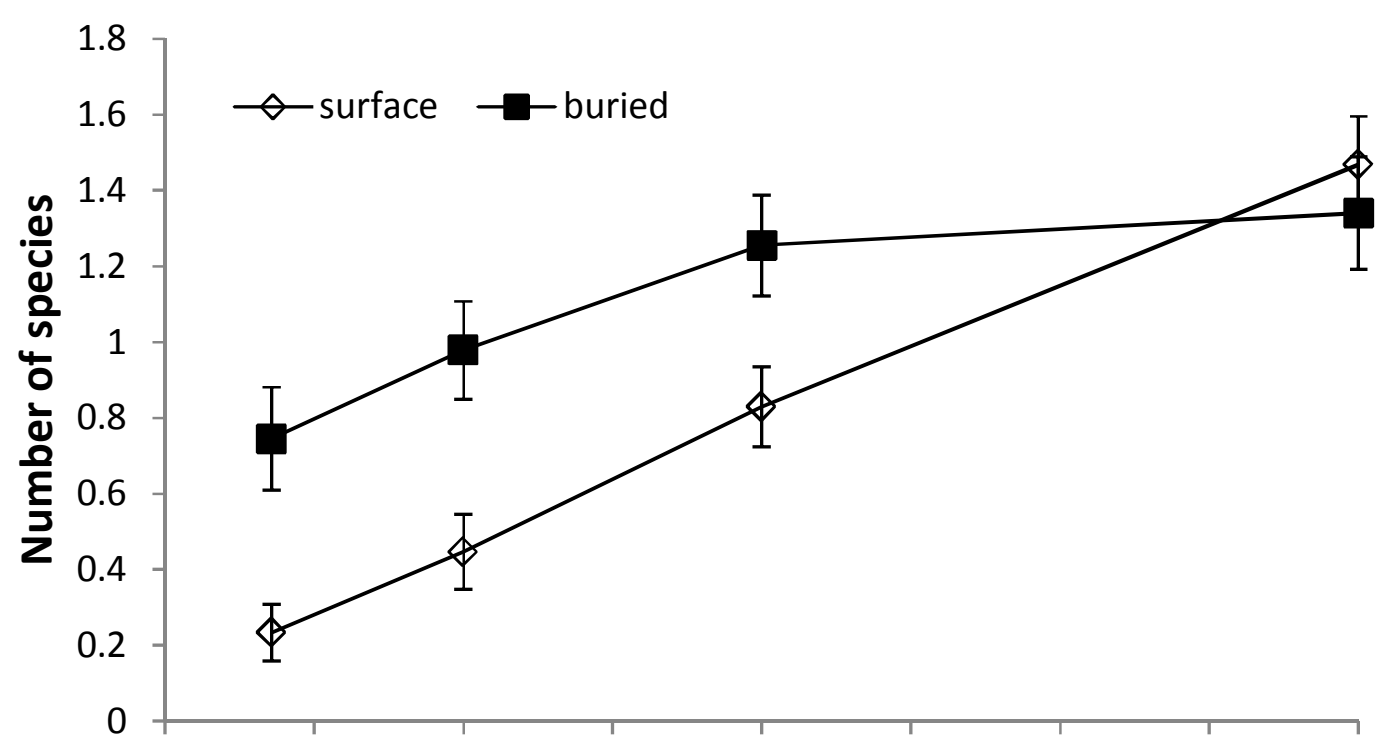


(c)

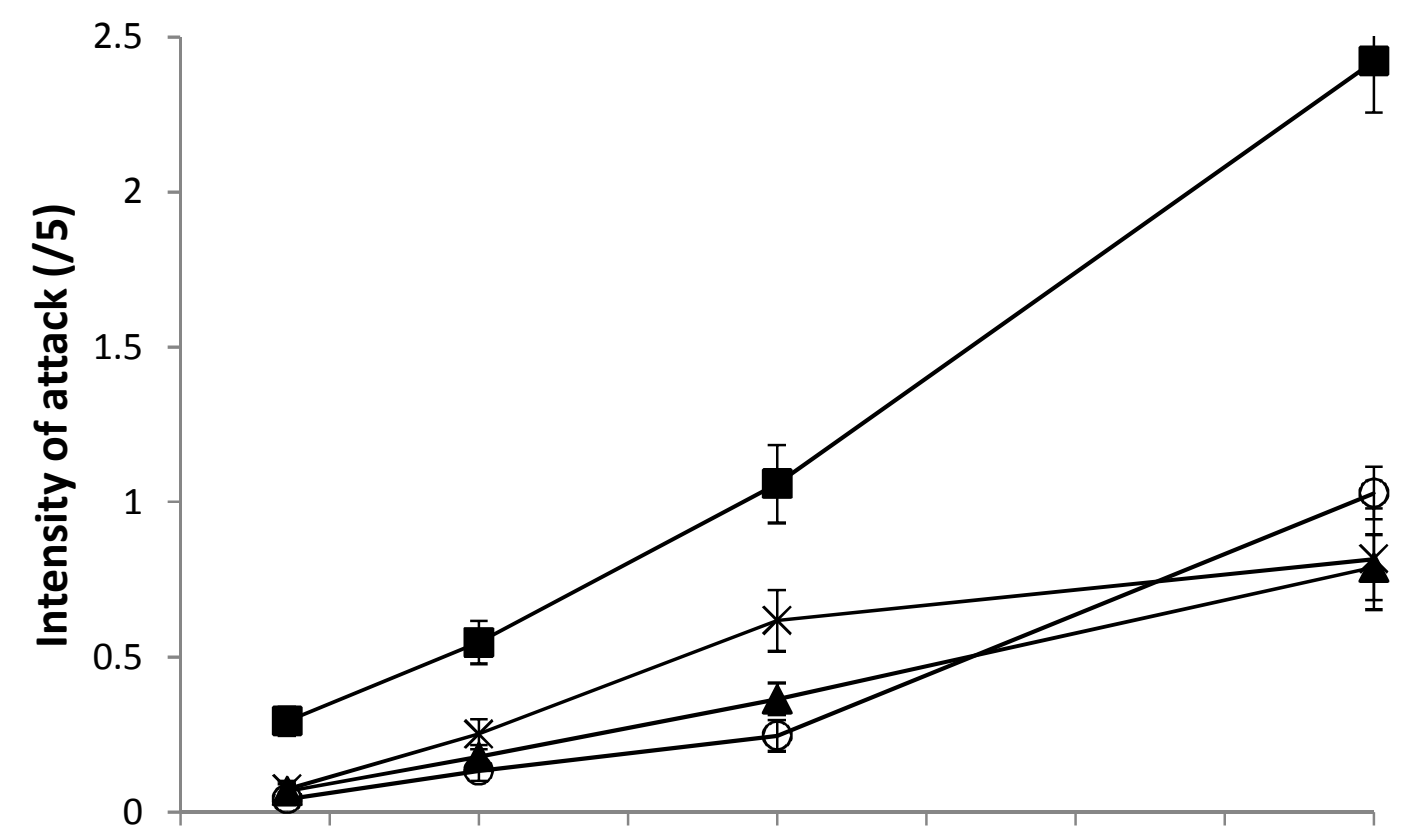

(d)

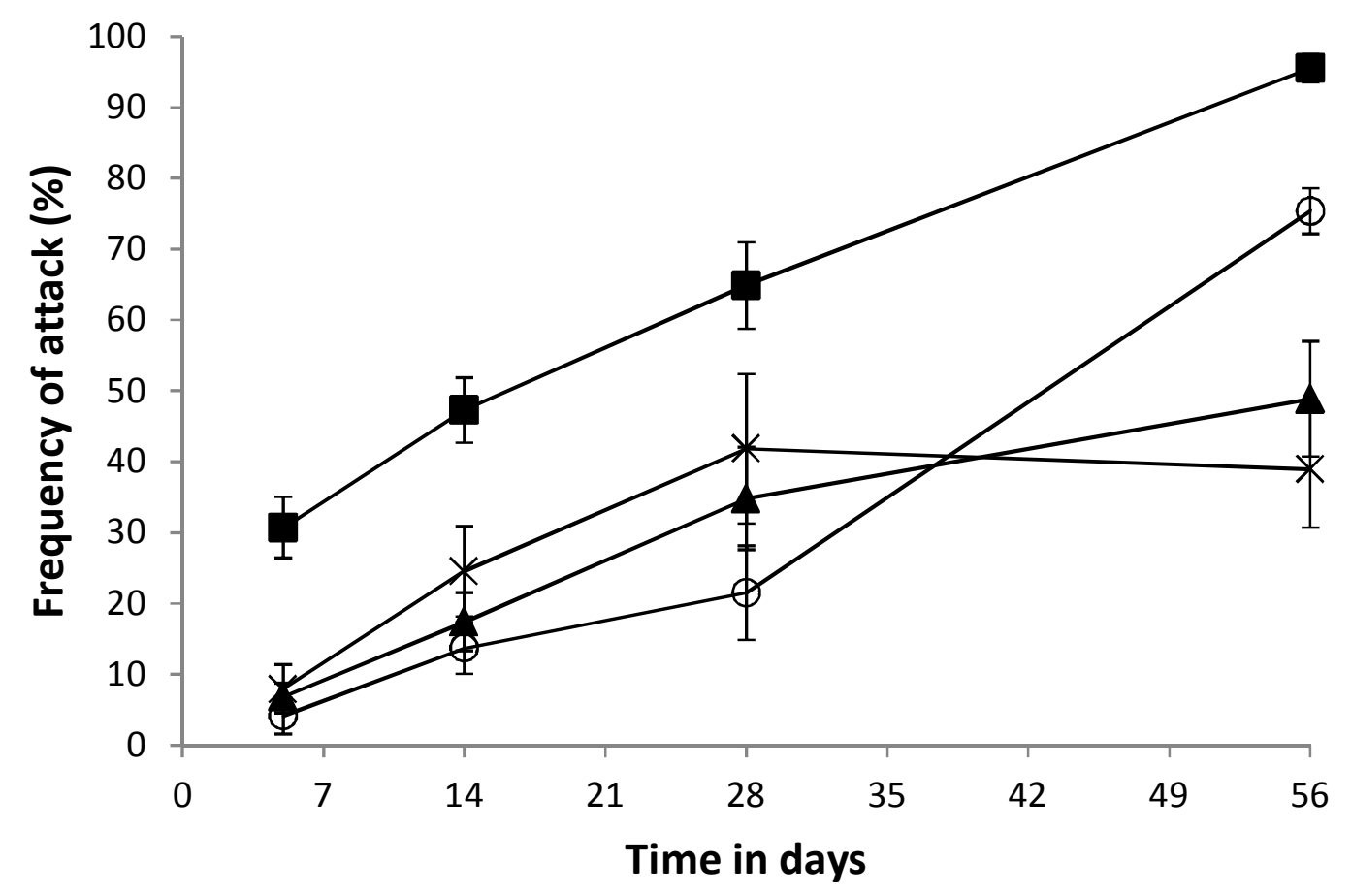

